\title{
Improvement of Strength and Consolidation Properties of Clayey Soil Using Ceramic Dust
}

\author{
Md. Akhtar Hossain, Md. Rashel Afride*, Naimul Haque Nayem \\ Department of Civil Engineering, Rajshahi University of Engineering \& Technology, Rajshahi, Bangladesh \\ Email address: \\ akhtar412002@yahoo.com (Md. A. Hossain), afrideaarib@gmail.com (Md. R. Afride), nayemruetcivil13@gmail.com (N. H. Nayem) \\ ${ }^{*}$ Corresponding author
}

To cite this article:

Md. Akhtar Hossain, Md. Rashel Afride, Naimul Haque Nayem. Improvement of Strength and Consolidation Properties of Clayey Soil Using Ceramic Dust. American Journal of Civil Engineering. Vol. 7, No. 2, 2019, pp. 41-46. doi: 10.11648/j.ajce.20190702.11

Received: March 20, 2019; Accepted: April 26, 2019; Published: May 15, 2019

\begin{abstract}
The ceramic industry, which comprises with wall tiles, bricks and roof tiles, floor tiles, sanitary accessories, refractory materials and ceramic materials for domestic and other uses, is generating a huge amount of ceramic wastes. Therefore, their problem of disposal is also a great concern. This research delineates the effects of waste ceramic dust on strength and consolidation characteristics of clayey soil. Soil samples were prepared with the inclusion of various proportion of ceramic dust with clayey soil. The test results indicate that Atterberg limits, optimum moisture content, compression index and swelling index decrease due to inclusion of different percentages of ceramic dust with the studied clayey soil. On the other hand, maximum dry density and soaked California Bearing Ratio (CBR) value increase with the increase of inclusion of ceramic dust upto $20 \%$. Further addition of ceramic dust had negative effects on these strength properties. It is recommended that ceramic dust upto $20 \%$ may be used for improving the detrimental properties of clayey soil.
\end{abstract}

Keywords: Clayey Soil, Ceramic Dust, Environmental Pollution, Conventional Tests, Improvement

\section{Introduction}

Clayey soil, also known as problematic or expansive soil has peculiar cyclic swell-shrink behaviour and for this reason construction on expansive soil always creates many problems for Civil engineers. When moisture content increases, the soil shows its swelling behaviour, but when the moisture decreases it shows shrinkage behaviour. During the volume change behaviour expansive soils cause large uplift pressures and upheaval of structures built on them [1]. Due to this movement, lightly loaded structures such as foundations, pavement, canal beds and linings, and residential structures established on them are severely damaged [1-4]. The enormous volume change is due to the presence of montmorillonite group of minerals. They are characterized by high cation exchange capacity [3], small particle size [5] and large specific area. Such soils should be stabilized to improve their properties for safe, reliable and well balanced construction on them. The requirements to improve the soil properties for construction works result in the use of a variety of stabilizers. One of them is the stabilization using dust/powder like waste materials with and without a binder like lime [6-9], cement [10,11] etc. Marble dust [12-15], quarry dust [16], sawdust ash [17], vitrified tiles powder [18], baryte powder [19], pyroclastic dust [20], brick powder [21] are some of the eminent dust/powder like waste materials which have been successfully utilized for stabilization of expansive soil. However, some of these stabilizers are either pricey or rare. Such as cement stabilization was adjudged the most impregnable due to its sufficiency. Howsoever, the increasing price of cement has delimited its use. It is consequently become essential to make use of common materials having excellent properties [22]. There is a large variety of materials available for the construction industries. The desire and sustainability of a specific material relies largely on its availability, nature of project, independent preference, durability, propinquity and financial consideration.

There has been a radical variation in the volume and properties of the solid waste owing to increase in population, urbanization, industrialization and change in lifestyle. As a result, solid wastes become more harmful to surroundings, and needs cautious disposal practices. 
It has been evaluated that about $30 \%$ of daily manufacturing in the ceramic industry goes as waste [23]. The ejection of that creates soil, water and air pollution. Ceramic dust is a cohesionless element, which can improve the characteristics of soil.

Koyuncu et al. (2004) added ceramic tile dust wastes up to $40 \%$ to find out its impact on swelling pressure and swelling potential of Na-bentonite, and observed that swelling pressure and swelling potential reduced by $86 \%$ and $57 \%$ respectively at $40 \%$ addition of ceramic tile dust waste [24].

Torgal and Jalali (2010) examined the feasibility of using ceramic wastes in concrete, and test results show that concrete with $20 \%$ cement replacement has a minor strength loss, but possess increased durability performance. While when concrete mixes with ceramic aggregates show better results than the control concrete mixtures concerning compressive strength, capillary water absorption, oxygen permeability and chlorine diffusion thus leading to more durable concrete structures [25].

Rajamannan et al. (2013) investigated the effect of addition of ceramic waste to clay materials, and concluded from chemical, mineralogical and morphological analyses, that ceramic waste can be added to the clay material with no detrimental effect on the properties of the sintered fire-clay products. The test results also indicate that the ceramic waste may be used as filler in ceramic bricks, thus enhancing the possibility of its reuse in a safe and sustainable way [26].

Zimbili et al. (2014) investigated the usage of ceramic waste in construction, and the results prove that the temperature used in the manufacturing of ceramic tiles (about $900{ }^{0} \mathrm{C}$ ) are sufficient to activate pozzolanic properties of clay. The investigation also shows that, after optimization (11\%-14\% substitution), the cement blend performs better with no morphological difference between the cement blended ceramic waste and that blended with other pozzolanic materials. Sanitary ware and electrical insulator porcelain wastes are some wastes investigated for usage as aggregates in concrete production. When optimized, both produced good results, better than when natural aggregates are used [27].
The present study focuses on the investigation of physical and engineering properties of ceramic dust and also observation of the improvement of deleterious properties of clayey soil by using it.

\section{Materials and Methodology}

This study was based on materials collection, laboratory tests, and to compare the effect of ceramic dust on the properties of clayey soil.

The materials were clayey soil and ceramic dust. Clayey soil sample was collected from Godagari, Rajshahi. Bangladesh. Waste ceramic tiles were collected from various construction projects, and converted into powder form by using jaw crusher machine. After passing the powder through \#200 No. ASTM sieve, the materials obtained called ceramic dust. Table 1 represents the different percentages of ingredients present in the ceramic dust used in the present study. Table 2 shows the basic properties of the clayey soil used in this study. All the properties are determined in the laboratory by following the ASTM standards [28].

Table 1. Ingredients of ceramic dust.

\begin{tabular}{ll}
\hline Ingredient & Percentage \\
\hline Aluminium Oxide, $\mathrm{Al}_{2} \mathrm{O}_{3}$ & $30.43 \%$ \\
Calcium Oxide, $\mathrm{CaO}$ & $4.16 \%$ \\
Ferric Oxide, $\mathrm{Fe}_{2} \mathrm{O}_{3}$ & $1.152 \%$ \\
Magnesium Oxide, $\mathrm{MgO}$ & $1.251 \%$ \\
Potassium Oxide, $\mathrm{K}_{2} \mathrm{O}$ & $1.009 \%$ \\
Silicon Oxide, $\mathrm{SiO}_{2}$ & $57.21 \%$ \\
Sodium Oxide, $\mathrm{Na}_{2} \mathrm{O}$ & $1.093 \%$ \\
\hline
\end{tabular}

Table 2. Index properties of soil.

\begin{tabular}{ll}
\hline Properties & Value \\
\hline Natural Water Content $(\%)$ & 12.34 \\
Liquid Limit $(\%)$ & 36.80 \\
Plastic Limit $(\%)$ & 18.66 \\
Plasticity Index $(\%)$ & 18.14 \\
Maximum Dry Density $\left(\mathrm{kN} / \mathrm{m}^{3}\right)$ & 17.81 \\
Optimum Moisture Content $(\%)$ & 15.46 \\
Specific Gravity $\left(\mathrm{G}_{\mathrm{s}}\right)$ & 2.65 \\
CBR $($ at $2.5 \mathrm{~mm})(\%)$ & 3.34 \\
\hline
\end{tabular}

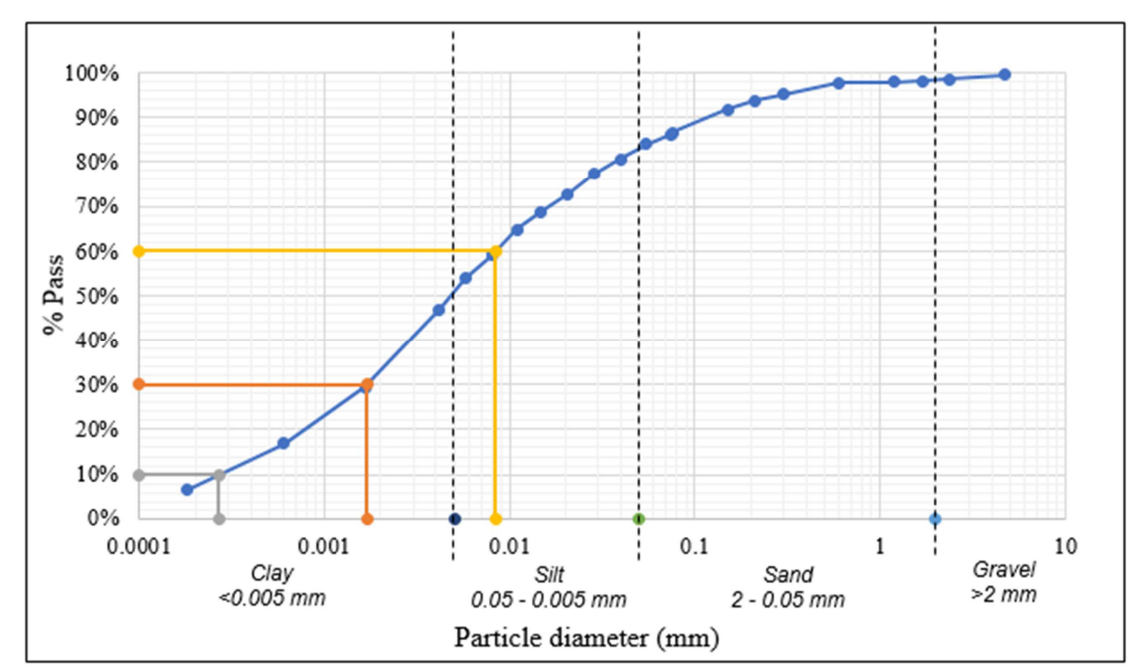

Figure 1. Particle size distribution curve of clayey soil. 
Figure 1 shows the particle size distribution curve for the studied clayey soil. According to the Unified Soil Classification System, the studied soil is classified as inorganic clay with medium plasticity, CL.

\section{Results and Discussion}

The variation of liquid limit of soil with the addition of various percentages of ceramic dust is shown in Figure 2. From the test results, it has been found out that liquid limit of soil goes on reducing from $36.80 \%$ to $22.36 \%$ when ceramic dust is added from 0 to $25 \%$. This happens because the surface area of the mixture (ceramic dust + soil) decreases due to the coarser particles of ceramic dust. However, it demands less water content to attain its liquid limit.

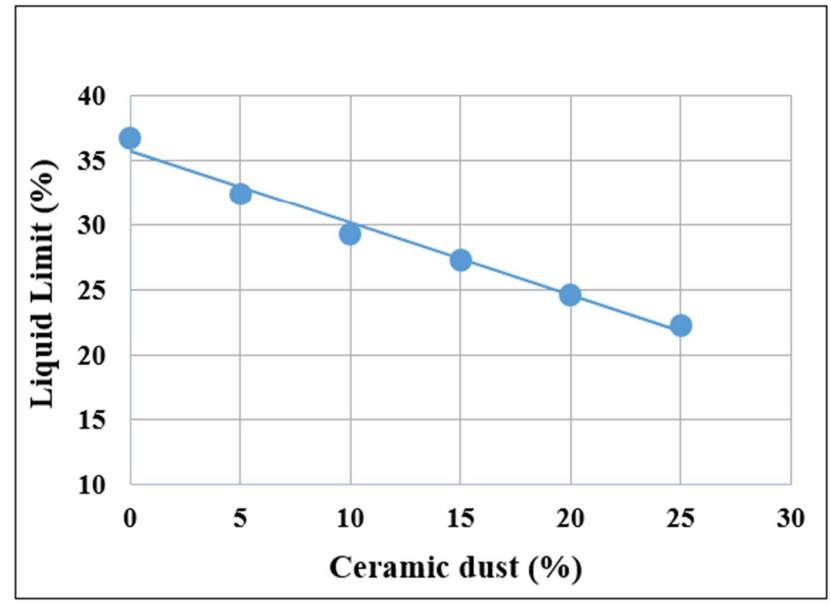

Figure 2. Variation of liquid limit with percentage of ceramic dust.

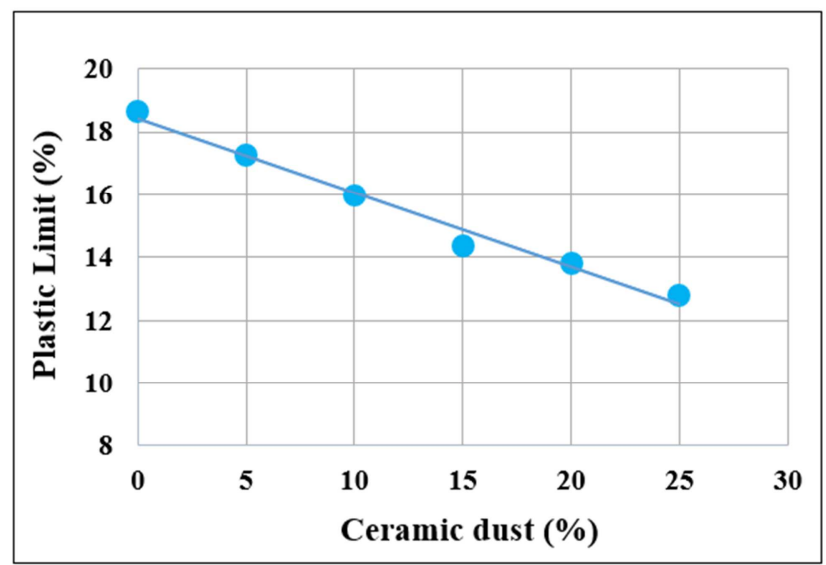

Figure 3. Variation of plastic limit with respect to ceramic dust.

Figure 3 presents the variation of plastic limit of soil with the inclusion of various percentages of ceramic dust. It is obvious from Figure 3 that the plastic limit of soil reduces from $18.66 \%$ to $12.81 \%$ for the inclusion of ceramic dust upto $25 \%$.

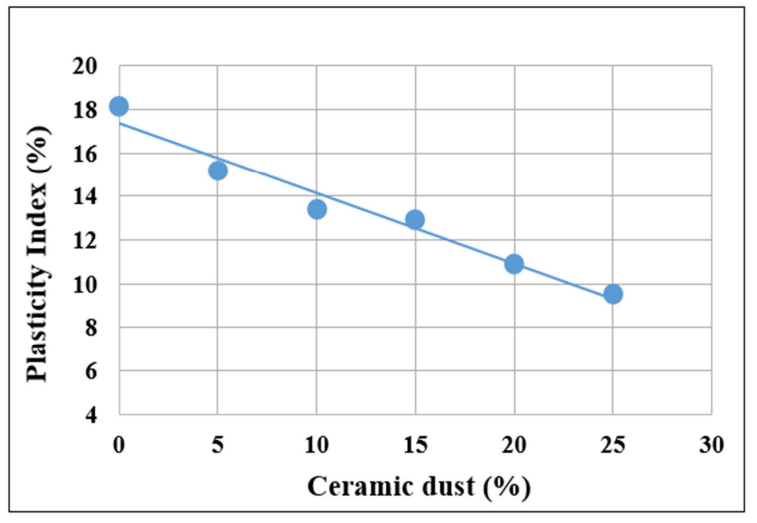

Figure 4. Variation of plasticity index with ceramic dust.

The variation of plasticity index with ceramic dust is shown in Figure 4. From Figure 4 it is prominent that the plasticity index goes on decreasing with addition of ceramic dust. The plasticity index decreases from $18.14 \%$ to $13.42 \%$ when ceramic dust is increased from 0 to $25 \%$. As ceramic dust is cohesionless, it was expected that it would reduce the plasticity index of soil and the result satisfies the expectation.

Publication [29] had also similar findings. A reduction in liquid limit, plastic limit and plasticity index with increase in ceramic dust content was observed. In the present study as well, a similar trend is seen in the soil characteristics with the addition of ceramic dust.

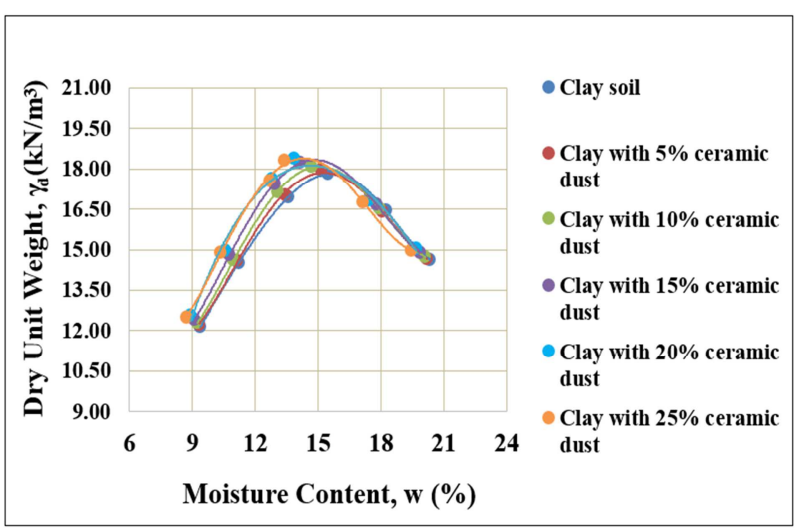

Figure 5. Variation of dry unit weight with moisture content for different samples.

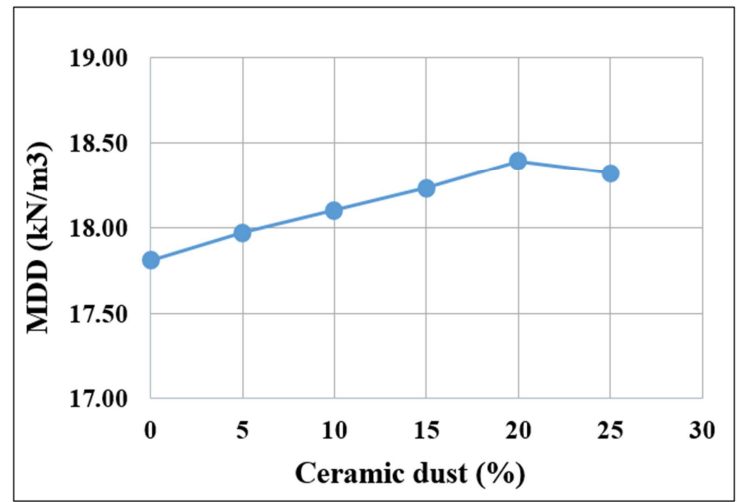

Figure 6. Variation of MDD with percentage of ceramic dust. 


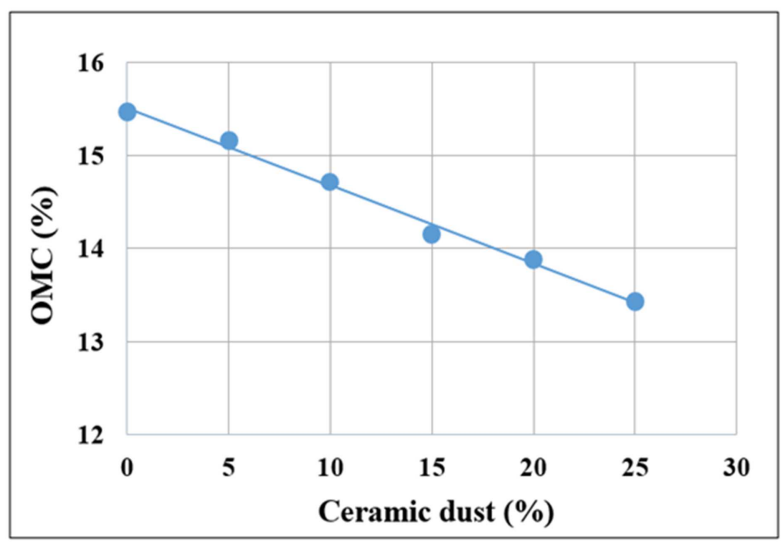

Figure 7. Variation of OMC with percentage of ceramic dust.

Modified Proctor test result for different samples is depicted in Figure 5. Figure 6 shows the variation of MDD with the inclusion of ceramic dust at various percentages. The MDD increases from $17.81 \mathrm{kN} / \mathrm{m}^{3}$ to $18.32 \mathrm{kN} / \mathrm{m}^{3}$ when $20 \%$ ceramic dust is added with the parent soil. The increase of MDD is due to the occupation of the void spaces of clayey soil by the ceramic dust particles, and the cementitious effect of $\mathrm{CaO}$ present in the ceramic dust. However, after $20 \%$, the availability of extra lime has a negative effect on the MDD. The variation of OMC with various proportion of ceramic dust is shown in Figure 7. The OMC goes on decreasing from $15.46 \%$ for parent soil to $13.42 \%$ for the inclusion of $25 \%$ ceramic dust. Due to the increase of coarser particles in the mix, the attraction for water molecule reduces, and hence OMC reduces.

With an increase in the ceramic percent, a reduction in OMC values and an increase in MDD values were noticed in the publication [29]. The maximum dry density (MDD) in almost all samples slightly increased with increasing ceramic dust additive which is related to the addition of fine additive with higher specific gravity with respect to the natural soil. The MDD increased from $15.6 \mathrm{kN} / \mathrm{m}^{3}$ to $18.1 \mathrm{kN} / \mathrm{m}^{3}$ when ceramic dust was increased from 0 to $30 \%$. But as a general trend, the optimum moisture content (OMC) exhibits a decrease with ceramic dust addition which might be a result of the increase of the coarser particles. The OMC decreased from $20.4 \%$ to $17.6 \%$ when ceramic dust was increased from 0 to $30 \%$.

The publication [13] reported a increase in MDD value from $1.735 \mathrm{gm} / \mathrm{cc}$ to $1.884 \mathrm{gm} / \mathrm{cc}$ with partial replacement of soil with marble powder. The reason behind increase of MDD is due to the fill-up of the void spaces and cementitious effect of $\mathrm{CaO}$ present in the marble powder. It was also found that $\mathrm{OMC}$ of the stabilized soil was decreased from $18.00 \%$ to $14.10 \%$ with partial replacement of soil with marble powder. In the present study as well, a similar trend is seen in the soil characteristics with the inclusion of different percentages of ceramic dust.

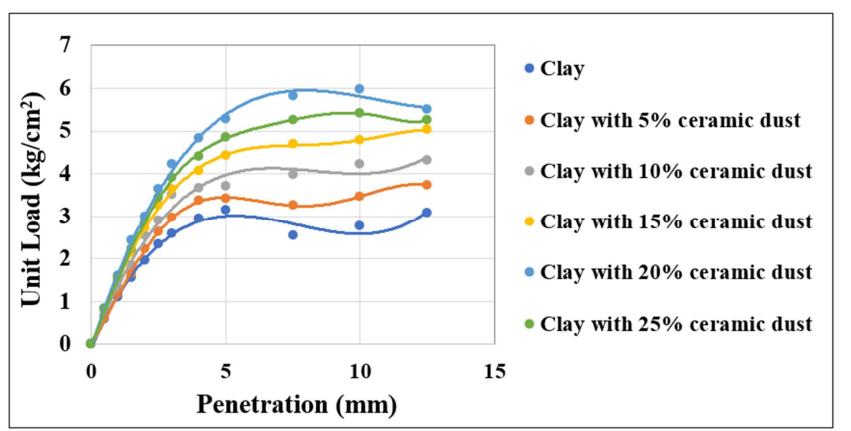

Figure 8. CBR (soaked) curves for different soil samples with the inclusion of ceramic dust.

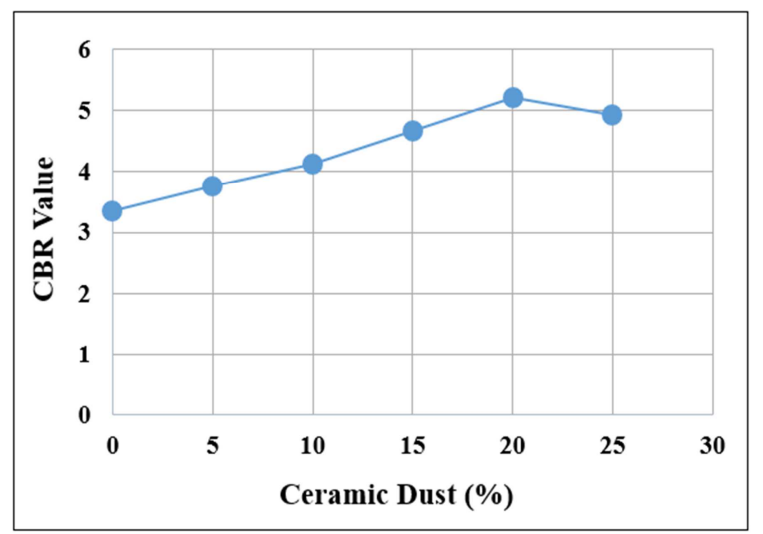

Figure 9. Variation of CBR (soaked) value for different samples.

The soaked CBR test results on clayey soil with the inclusion of various percentages of ceramic dust are illustrated in Figure 8. Figure 9 states the variation of soaked CBR value for different samples.

It is obvious that when ceramic dust is added from 0 to $20 \%$, the CBR value rises from 3.34 to 5.21 . The CBR value increases due to both the coarser particles and lime present in the ceramic dust, which acts as a cementitious material. The pozzolanic reaction of lime present in ceramic dust with the amorphous Silica and Alumina present in soil is responsible for the rise in $\mathrm{CBR}$ value. With the addition of ceramic dust beyond $20 \%$, extra lime reacts with inadequate amorphous Silica and Alumina present in soil and results in carbonation reaction and strength decreases.

Sabat [29] also found that with increase in percentage of ceramic dust, the soaked CBR of soil went on increasing. The soaked CBR increased from $1.6 \%$ to $4 \%$ when ceramic dust was increased from 0 to $30 \%$. There was $150 \%$ increase in soaked CBR of soil at this percentage of ceramic dust as compared to untreated soil. As MDD increases with increase in the percentage of ceramic dust, it results in increase in soaked CBR value of the soil.

Publication [13] provides similar results. CBR of the stabilized soil was increased from 2.46 to 6.07 with partial replacement of soil with marble powder. The reason behind the increase in CBR value is both due to coarser particles as well as lime present in the waste marble powder which behaves as cementitious material. Due to this reason the bond between clay particles and waste marble powder becomes 
strong and the load bearing capacity has been increased.

The consolidation test results on clayey soil with the inclusion of various percentages of ceramic dust are shown in Figures 10, 11 and 12. The Figures yield that both the compression and swelling index decrease with the inclusion of ceramic dust. Reduction of these indices indicates that the detrimental property of the clayey soil may have been improved. The attraction for water molecule reduces due to the reduction of clay content of clayey soil by replacement of non-cohesive ceramic dust.

The publication [30] reported that Compression Index and Swelling Index decreased up to $27 \%$ and $31 \%$, respectively, when the soil was mixed with $25 \%$ of limestone powder. This addition decreases the compressibility of the soil as the slope of the virgin and rebound consolidation curves are reduced. This lower compressibility of the mixed soil is attributed to the fine aggregates of the limestone powder dust filling the voids of the natural soil.

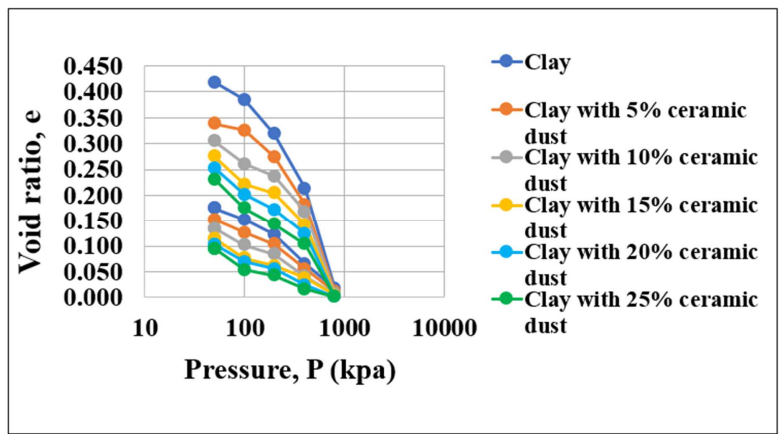

Figure 10. e-logP curve for different samples.

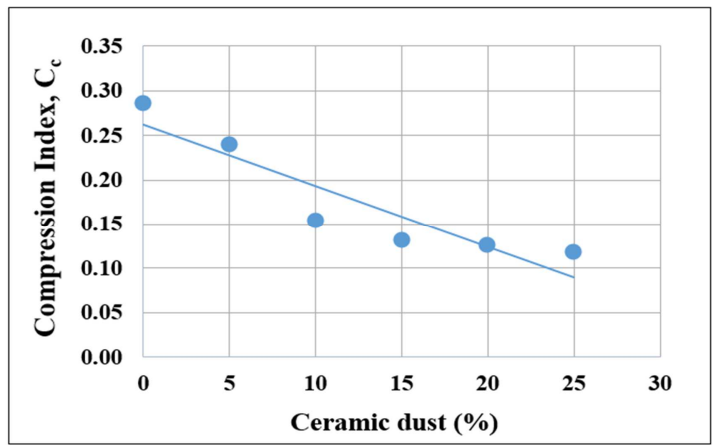

Figure 11. Variation of Compression Index $\left(C_{c}\right)$ with percentage of ceramic dust.

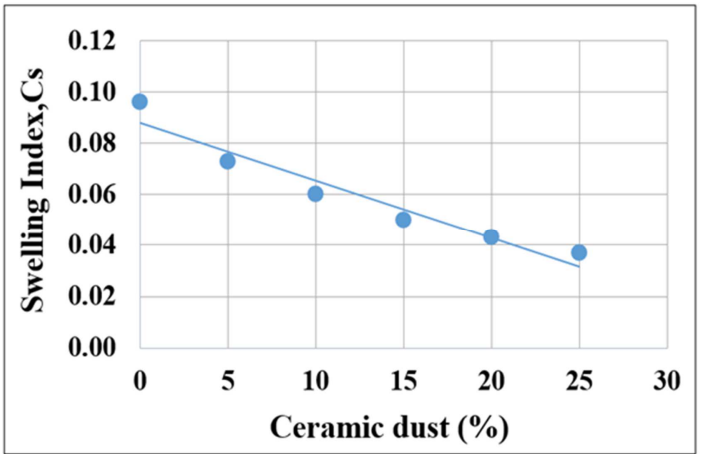

Figure 12. Variation of Swelling Index $\left(C_{s}\right)$ with percentage of ceramic dust.

\section{Conclusion}

A series of laboratory tests has been conducted on the untreated clayey soil and the ceramic dust treated clayey soil. The following conclusions may be drawn by considering the test results and discussion presented in the previous sections:

i The atterberg limits go on decreasing with the percentages of addition of ceramic dust.

ii The MDD goes on increasing and OMC goes on decreasing with increase in percentage of ceramic dust upto $20 \%$. Further addition of ceramic dust has negative effect on MDD.

iii The soaked CBR goes on increasing with increase in percentage of ceramic dust upto $20 \%$. However, when $25 \%$ ceramic dust is added, the CBR value decreases.

iv Compression index and swelling index go on decreasing with percentage of ceramic dust.

\section{References}

[1] Bhuvaneshwari, S., Robinson, R. G., and Gandhi, S. R. (2013). Behaviour of Lime Treated Cured Expansive Soil Composites, Indian Geotechnical Journal, 44(3), 278-293.

[2] Al-Mukhtar, M., Lasledj, A., and Alcover, J. F. (2010). Behaviour and mineralogy changes in lime-treated expansive soil at $20^{\circ} \mathrm{C}$, Applied Clay Science, 50(2), 191-198.

[3] Celik, E., and Nalbantoglu, Z. (2013). Effects of ground granulated blastfurnace slag (GGBS) on the swelling properties of lime-stabilized sulfate-bearing soils, Engineering Geology, 163, 20-25.

[4] Chen, F. H. (1988). Foundations on expansive soils, Elsevier Science Publication, New York.

[5] Fityus, S., and Buzzi, O. (2009). The place of expansive clays in the framework of unsaturated soil mechanics, Applied Clay Science, 43(2), 150-155.

[6] Bhuvaneshwari, S., \& Raja, S. (2017). Stabilization of expansive soils - Evaluation of the behaviour with lime, International Journal of Civil Engineering and Technology, Vol. 8, Issue 7, pp. 1003-1013, ISSN Print: 0976-6308 and ISSN Online: 0976-6316.

[7] Chindris, L., Stefanescuu, D. P., Ladislau, R., Radeanu, C., and Popa, C. (2017). Expansive Soil Stabilisation-General Considerations, 17th International Multidisciplinary Scientific Geoconference, 10.5593/sgem2017/32/S13.033.

[8] Garzón, E., Cano, M., O`Kelly, B. C., and Sánchez-Soto, P. J. (2016). Effect of lime on stabilization of phyllite clays, Applied Clay Science, 123, 329-334.

[9] Leite, R., Cardoso, R., Cardoso, C., Cavalcante, E., and Freitas, O. De. (2016). Lime stabilization of expansive soil from Sergipe - Brazil, E3S Web of Conferences, 9, 1-6.

[10] Marathe, S., Rao, B. S., and Kumar, A. (2015). Stabilization of Lithomargic Soil Using Cement and Randomly Distributed Waste Shredded Rubber Tyre Chips, International Journal of Engineering Trends and Technology, Vol. 23, No. 1, pp. 284288, ISSN: 2231-5381. 
[11] Pandey, A., and Rabbani, A. (2017). Soil Stabilisation Using Cement, International Journal of Civil Engineering and Technology, Vol. 8, Issue 6, pp. 316-322, ISSN Print: 09766308, ISSN Online: 0976-6316.

[12] Babu, S. V., \& Sharmila, M. (2017). Soil Stabilisation Using Marble Dust, International Journal of Civil Engineering and Technology, Vol. 8, Issue 4, pp. 1706-1713.

[13] Bansal, H., Sidhu, G. S. (2016). Influence of Waste Marble Powder on Characteristics of Clayey Soil, International Journal of Science and Research, Vol. 5, Issue 8, ISSN (Online): 2319-7064.

[14] Sabat, A. K., and Nanda, R. P. (2011). Effect of marble dust on strength and durability of rice husk ash stabilised expansive soil, International Journal of Civil and Structural Engineering, Vol.1 (4), pp. 939-948.

[15] Zumrawi, Magdi and A. E. Abdalla, Eman. (2018). Stabilisation of Expansive Soil Using Marble Waste Powder, 2nd Conference of Civil Engineering, CCE 2018, Sudan.

[16] Sabat, A. K. (2012). A study on some geotechnical properties of lime stabilized expansive soil -quarry dust mixes, International Journal of Emerging Trends in Engineering and Development, Vol. 1(2), pp. 42-49.

[17] Karim, H., Mohsen, M., and Nsaif, M. (2018). Stabilization of soft clayey soils with sawdust ashes, MATEC Web of Conferences, 162. 01006. 10.1051/matecconf/201816201006.

[18] Prasad, A. S. S. V., Prasad, D. S. V, and Babu, R. D. (2015). Efficiency of Calcium Chloride and Vitrified Tiles Sludge on the Strength Characteristics of Expansive Soil, International Journal of Advanced Research in Education and Technology, 2(3), 202-205.

[19] Srinivasulu, G., and Rao, A. V. N. (1995). Efficacy of baryte powder as a soil stabilizer, Journal of the Institution of Engineers (I), Vol.76, Nov. pp. 129-131.

[20] Ene, E., and Okagbue, C. (2009). Some basic geotechnical properties of expansive soil modified using pyroclastic dust, Engineering Geology, Vol.107(1-2), pp 61-65.

[21] Abd EI-Aziz, M., and Abo-Hashema, M. A. (2012). Measured effects on engineering properties of clayey subgrade using lime-homra stabiliser, International Journal of Pavement Engineering, DOI: 10.1080/10298436.2012.655739.
[22] Toryila, T., Singh, S., and Kumar, A. (2018). Expansive Soil Stabilisation Using Industrial Solid Wastes a review, International Journal of Advanced Technology in Engineering and Science, Vol. 4, Issue 9, ISSN : 2348-7550.

[23] Binici, H. (2007). Effect of crushed ceramic and basaltic pumice as fine aggregates on concrete mortar properties, Elsevier Ltd., construction and building materials Vol.21, pp. 1191-1197.

[24] Koyuncu, H., Guney, Y., Yilmaz, G., Koyuncu, S., and Bakis, R. (2004). Utilization of Ceramic wastes in the construction sector, Key Engineering Materials, Vols. 264-268, pp. 25092512.

[25] Torgal and Jalali (2010). Reusing ceramic wastes in concrete, Elsevier Ltd., Construction and Building materials, 24: 832838 .

[26] Rajamannan, B., Viruthagiri, G. and Jawahar, K. S. (2013). Effect of grog addition on the technological properties of ceramic brick, International Journal of Latest Research in Science and Technology, ISSN (Online): 2278-5299 Volume 2, Issue 6: Page No.81-84, November-December 2013.

[27] Zimbili, O., Salim, W., and Ndambuki, M. (2014). A Review on the Usage of Ceramic Wastes in Concrete Production, World Academy of Science, Engineering and Technology International Journal of Civil, Environmental, and Structural, Construction and Architectural Engineering Vol. 8, No. 1, 2014.

[28] American Society for Testing and Materials. (1992). ASTM D2487-90: 1992. Standard test method for classification of soils for engineering purposes (Unified Soil Classification System), Annual Books of ASTM Standards, Vol. 04.08, Section 4, Philadelphia, Penn: 326-336.

[29] Sabat, A. K. (2012). Stabilization of Expansive Soil Using Waste Ceramic Dust, Electronic Journal of Geotechnical Engineering, vol. 17, no. Bund. Z, pp. 3915-3926.

[30] Pastor, J. L., Tomás, R., Cano, M., Riquelme, A., and Erick, G. (2019). Evaluation of the Improvement Effect of Limestone Powder Waste in the Stabilization of Swelling Clayey Soil, Sustainability, 11. 679. 10.3390/su11030679. 